\title{
Complete atrioventricular block associated with clozapine intoxication: case report
}

\author{
Mehmet Türe ${ }^{1}$, Meki Bilici ${ }^{1}$, Alper Akın¹, Fikri Demir ${ }^{1}$, Hasan Balık ${ }^{1}$, Savaş Mert Darakçı ${ }^{2}$ \\ ${ }^{1}$ Division of Pediatric Cardiology, ${ }^{2}$ Department of Pediatrics, Dicle University Faculty of Medicine, Diyarbakır, Turkey. \\ E-mail: drture21@gmail.com
}

Received: 23rd March 2018, Revised: 16th May 2018, Accepted: 31st May 2018

\begin{abstract}
SUMMARY: Türe M, Bilici M, Akın A, Demir F, Balık H, Darakçı SM. Complete atrioventricular block associated with clozapine intoxication: case report. Turk J Pediatr 2019; 61: 618-621.

Clozapine is one of the atypical anti-psychotic drugs used in the treatment of resistant schizophrenia. Although cardiac side-effects are rare, it has been reported that there may be development of myocarditis, dilated cardiomyopathy, postural orthostatic hypotension and prolonged QT duration. Complete atrioventricular (AV) block is characterized by the inability to transmit all of the atrial signal to the ventricles. Causes may be congenital, idiopathic or acquired which are associated with surgery, infection, or muscle disease. $\mathrm{AV}$ block is extremely serious and permanent pacemaker insertion is usually necessary for all patients. Complete AV block may develop due to clozapine intoxication through increase in vagal tonus, sinoatrial node (SN) and the inhibition of atrioventricular node signalling. The case presented here is of a 15-year old female patient who developed AV total cardiac block associated with the taking of clozapine in a suicide attempt.
\end{abstract}

Key words: clozapine, complete atrioventricular block, intoxication.

Clozapine is a medication in the dibenzodiazepine group which is used as an anti-psychotic in the treatment of resistant schizophrenia. As minor cardiovascular side-effects, orthostatic hypotension, sinus tachycardia may be commonly seen. ${ }^{1-2}$ Fatal complications such as myocarditis and dilated cardiomyopathy have been reported less often. On electrocardiography (ECG), sinus tachycardia, T-wave inversion, prolonged QT duration, ST flattening and ST depression may also be seen..$^{3-6}$ Complete atrioventricular block is characterized by the inability of atrial signals to reach any of the ventricles, may be seen congenitally or associated with acquired causes such as cardiac surgery, infection, muscle disease or medications. ${ }^{7}$ If complete AV block is not diagnosed early, a broad clinical table may be seen from reduced quality of life to syncope and death. A proportion of these patients may require a pacemaker at some point in their lives. Therefore, early diagnosis is of vital importance. This case report can be considered to make an important contribution to literature in respect of attention to be paid to complete AV block associated with clozapine.

\section{Case Report}

A 15-year old girl was brought to the Emergency Department (ED) one hour after taking 10 pieces of clozapine $250 \mathrm{mg}$ tablets with the intention of committing suicide. The patient's general condition was good and vital signs were stable so stomach irrigation was applied and active carbon was given. As 2nd and 3rd degree AV blocks were seen on the ECG and heart rate was $60 \mathrm{bpm}$ (Fig. 1), the patient was admitted to the Intensive Care Unit (ICU). While under observation in the ICU, the patient was conscious. The blood pressure values and system examination findings were normal. Complete blood count, serum electrolytes, liver and kidney function tests, troponin, CK-MB, pro-BNP, PT, aPTT, INR and blood gases were all evaluated as normal. On the transthoracic echocardiography applied 


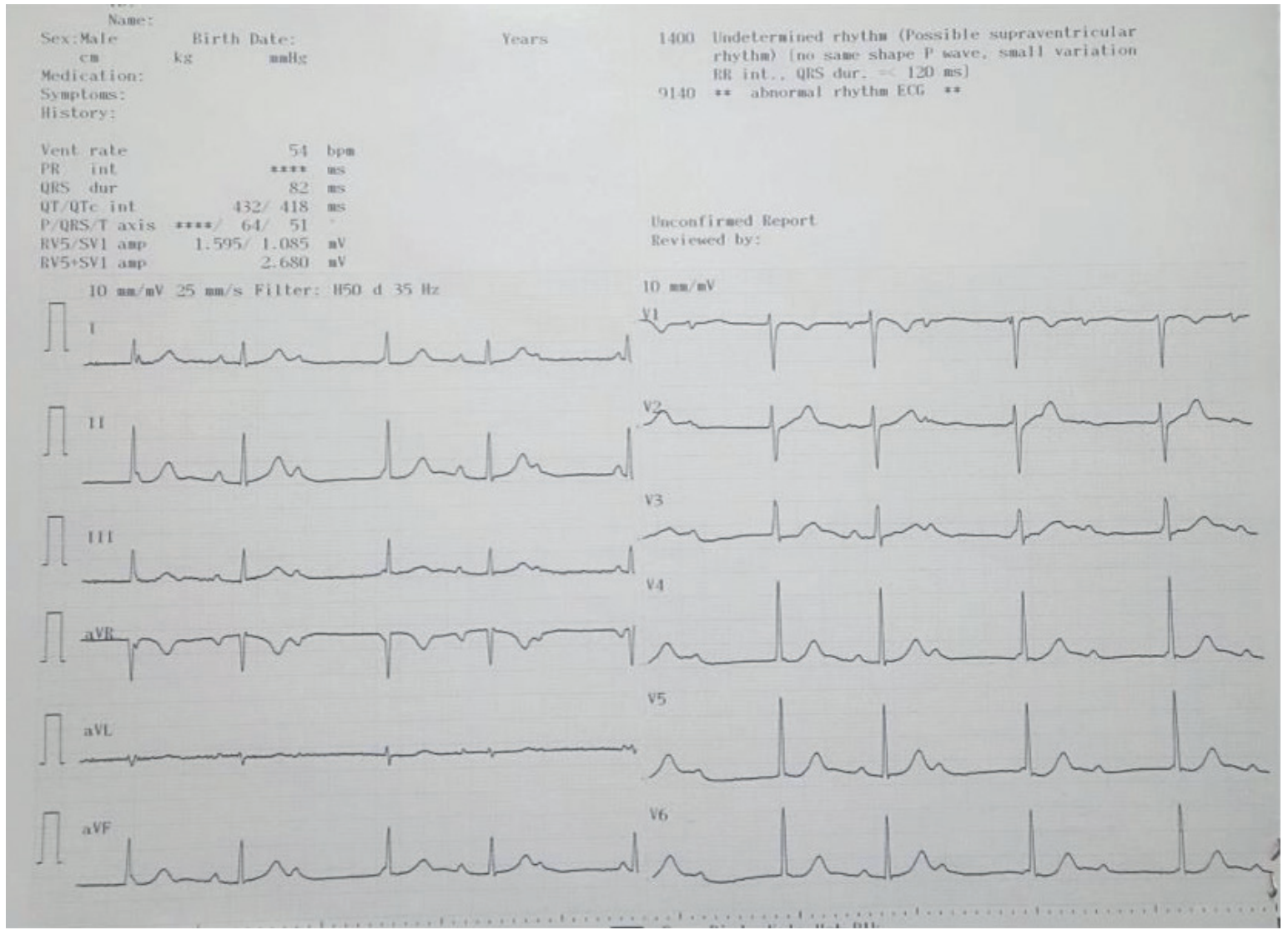

Fig. 1. Electrocardiography of the patient showing complete atrioventricular block.

at the bedside, left ventricle ejection fraction (LVEF) was 65\%, left ventricle diastole end diameter (LVEDd) was $45 \mathrm{~mm}$, and mild mitral regurgitation was determined. On the 24-hour Holter ECG, intermittent complete AV block, 2:1 AV block, occasional ventricular extra-systole (VES) and mean heart beat rate of $54 \mathrm{bpm}$ were determined. As an ECG had been taken of the patient 2 years previously and the results were first degree AV block (Fig. 2), corrected QT (QTc): $400 \mathrm{~ms}$, the complete $\mathrm{AV}$ block was thought to be associated with the clozapine intoxication. The patient had not used clozapine before. With the data available, the patient was accepted as asymptomatic complete AV block. In the clinical followup, the patient was hemodynamically stable and mean heart rate was $54 \mathrm{bpm}$ so she was discharged with follow-up appointments. The troponin and Pro-BNP values and transthoracic echocardiography findings examined on the 1 st day and at the 1st week, 1st month and 3rd month were determined as normal for her age. At the 1-week, 1-month, 3-month and 12-month follow-up examinations, there were no symptoms, intermittent complete AV block continued on the ECG and the mean heart rate was determined as $55 \mathrm{bpm}, 57 \mathrm{bpm}$ and 55 bpm, respectively. It was decided to continue the clinical follow-up of the patient.

The family of the patient gave permission for the publication of this case.

\section{Discussion}

Clozapine is a second-generation, antipsychotic medication which is used in resistant schizophrenia that is unresponsive to frequently used antipsychotic medications and other psychotic disorders. ${ }^{8}$ Cardiac side-effects such as postural orthostatic hypotension, myocarditis, dilated cardiomyopathy and prolonged QT interval can be seen from clozapine, which is an atypical neuroleptic dibenzodiazepan. ${ }^{9}$ Although dilated cardiomyopathy and myocarditis are not frequently seen, they can be fatal side-effects. ${ }^{5}$ In a previous study of patients who developed 


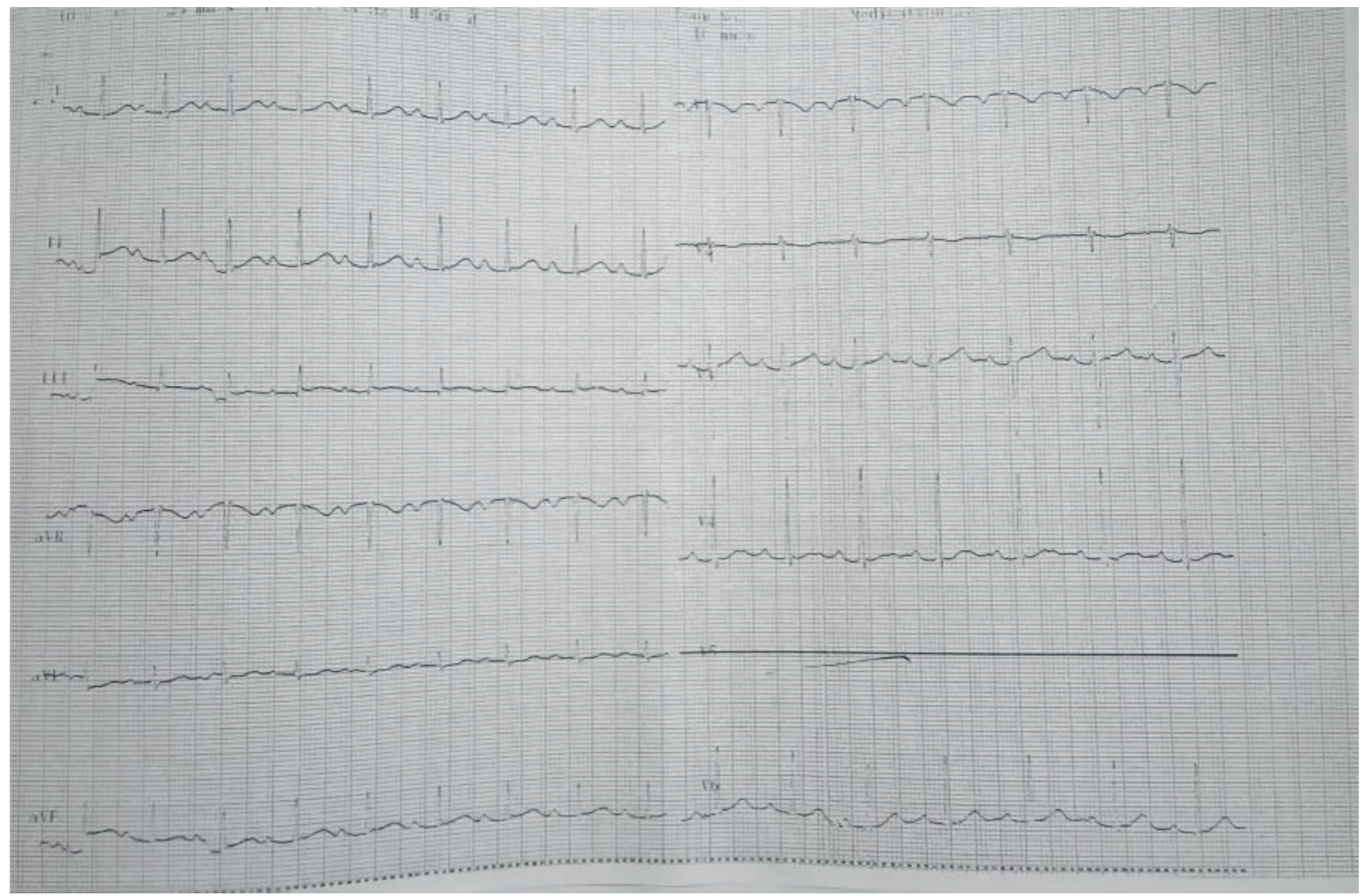

Fig. 2. Electrocardiography of the patient 2 years before, showing first degree atrioventricular block.

myocarditis associated with clozapine, myocarditis developed in the first 3 weeks in all the patients. ${ }^{3}$ In a study by Haas et al. ${ }^{10}$, it was shown that myocarditis developed in $0.7 \%-2 \%$ of patients taking a treatment dose of clozapine. Another study in England showed that cardiomyopathy developed in $0.2 \%$ of patients taking clozapine. ${ }^{11}$ In patients who develop myocarditis and cardiomyopathy associated with clozapine, firstly the clozapine must be terminated and then supportive treatment must be given. ${ }^{12}$ Patients who could develop left ventricle dysfunction should be followed up regularly both clinically and with ECG. Krobert et al. ${ }^{13}$ identified that clozapine inhibited depolarisation of the sinus node in vitro and reduced adrenergic sensitivity. Eosinophilic myocarditis is an uncommon form of myocarditis characterized in most cases by myocardial inflammation formed from eosinophils. It has been reported that it can develop at the rate of $0.2 \%-3 \%$ with long-term clozapine use. ${ }^{14}$ Vaddadj et al. ${ }^{15}$ reported that as clozapine reduced the level of selenium, which functions in the inhibition of myocarditis, the repair mechanism for damage to the AV communication system was impaired and therefore clozapine inhibited AV communication. As seen in the current case, complete AV cardiac block can develop because of the inhibition of AV communication.

Although rare, even though various cardiac side-effects are seen at certain rates associated with clozapine, only one publication was found which reported the development of AV complete cardiac block associated with clozapine. Therefore, the current case can be considered to contribute to the literature. In patients presenting with clozapine intoxication or who use clozapine, troponin and pro-BNP levels must be examined and echocardiography must be applied to discount cardiomyopathy and heart failure. Routine ECG must be taken and cardiac monitoring must be applied in respect to AV complete block. When necessary 24-hour Holter ECG should be applied and patients must be closely followed-up in respect to AV complete block, which can be fatal. 


\section{REFERENCES}

1. Young CR, Bowers MB Jr, Mazure CM. Management of the adverse effects of clozapine. Schizophr Bull 1998; 24: 381-390.

2. Rohde C, Polcwiartek C, Kragholm K, Ebdrup BH, Siskind D, Nielsen J. Adverse cardiac events in outpatients initiating clozapine treatment: A nationwide register-based study. Acta Psychiatr Scand 2018: 137: 47-53

3. Killian JG, Kerr K, Lawrence C, Celermajer DS. Myocarditis and cardiomyopathy associated with clozapine. Lancet 1999; 354: 1841-1845.

4. Bellissima BL, Tingle MD, Cicović A, Alawami M, Kenedi C. A systematic review of clozapine-induced myocarditis. Int J Cardiol 2018; 259: 122-129.

5. Knoph KN, Morgan RJ 3rd, Palmer BA, et al. Clozapine-induced cardiomyopathy and myocarditis monitoring: A systematic review. Schizophr Res 2018; 199: 17-30.

6. Hollingworth SA, Winckel K, Saiepour N, Wheeler AJ, Myles N, Siskind D. Clozapine-related neutropenia, myocarditis and cardiomyopathy adverse event reports in Australia 1993-2014. Psychopharmacology (Berl) 2018; 235: 1915-1921.

7. Friedman DM, Duncanson LJ, Glickstein J, Buyon JP. A review of congenital heart block. Images Paediatr Cardiol 2003; 16: 36-48.

8. McEvoy JP, Lieberman JA, Stroup TS, et al; CATIE Investigators. Effectiveness of clozapine versus olanzapine, quetiapine, and risperidone in patients with chronic schizophrenia who did not respond to prior atypical antipsychotic treatment. Am J Psychiatry 2006; 163: 600-610.
9. Makhoul B, Hochberg I, Rispler S, Azzam ZS Dilated cardiomyopathy: An unusual complication of clozapine therapy. Nat Clin Pract Cardiovasc Med 2008; 5: 566-570.

10. Haas SJ, Hill R, Krum H, et al. Clozapine-associated myocarditis: A review of 116 cases of suspected myocarditis associated with the use of clozapine in Australia during 1993-2003. Drug Saf 2007; 30: $47-$ 57.

11. Committee on Safety of Medicines.Myocarditis with antipsychotics: Recent cases with clozapine (Clozaril). Curr Prob Pharmacovigilance 1993; 19: 9-10.

12. Reinders J, Parsonage W, Lange D, Potter JM, Plever S. Clozapine-related myocarditis and cardiomyopathy in an Australian metropolitan psychiatric service. Aust N Z J Psychiatry 2004; 38: 915-922.

13. Krobert KA, Andressen KW, Levy FO. Heterologous desensitization is evoked by both agonist and antagonist stimulation of the human $5-\mathrm{HT}(7)$ serotonin receptor. Eur J Pharmacol 2006; 532: 1-10.

14. Sahpaz A, Pehlivan S, Turkkan D, Özdemir Kara D, Alkurt Alkan H. Eosinophilic myocarditis in long term use of antipsychotics: Case series and review of the literature. BullClinPsychopharmacol 2016; 26: 417-421.

15. Vaddadi KS, Soosai E, Vaddadi G. Low blood selenium concentrations in schizophrenic patients on clozapine. Br J Clin Pharmacol 2003; 55: 307-309. 